\title{
Hacia una historia trasnacional de las izquierdas bolivianas.
}

Reseña de Andrey Schelchkov y Pablo Stefanoni (Coords.). Historia de las izquierdas bolivianas. Archivos y documentos (1920-1940). La Paz: Vicepresidencia del Estado Plurinacional de Bolivia / Centro de Investigación Sociales /Instituto de Historia Universal de la Academia de Ciencias de Rusia, 2016, 392 págs.

Oscar A. Acosta Torres

oscacosta1991@gmail.com

Instituto Botticelli, México

Cita sugerida: Acosta Torres, O. A. (2022). Hacia una historia trasnacional de las izquierdas bolivianas [Revisión del libro Historia de las izquierdas bolivianas. Archivos y documentos (1920-1940) por A. Schelchkov y P. Stefanoni]. Sociohistórica, 49, e165.

https://doi.org/10.24215/18521606e165

La Historia de las izquierdas bolivianas. Archivos y documentos (1920-1940), coordinada por los especialistas Andrey Schelchkov y Pablo Stefanoni, propone un nuevo acercamiento a la conformación y desarrollo de las izquierdas radicales en Bolivia, aportando distintas perspectivas de estudio, así como un interesante cuerpo documental extraído de archivos soviéticos, bolivianos, mexicanos y argentinos. A partir de la idea de "comunidades imaginadas" - propuesta por Benedict Anderson-, los coordinadores de la obra plantean que los comunistas de diferentes países, latinoamericanos en este caso, se identificaban con una "hermandad horizontal" que ideológica y políticamente justificaba la lucha, los esfuerzos y los sacrificios de los miembros de esta comunidad imaginada. Al estudiar la complejidad política, social y cultural de las convulsas décadas de 1920 y 1930, esta propuesta metodológica parece sin duda ser asertiva, en el sentido de que la historia de 
las izquierdas latinoamericanas trasciende las barreras nacionales a partir de la conformación de redes a lo largo y ancho del continente.

Los ensayos analíticos que se encuentran en la primera parte del libro, escritos por diferentes especialistas, dejan ver, precisamente, lo anteriormente mencionado: para entender la historia de las izquierdas bolivianas resulta necesario considerar acontecimientos, procesos o personajes externos. El papel que jugó la Komintern en Bolivia, el surgimiento de las primeras izquierdas radicales en el país, la heterogeneidad ideológica de los movimientos e incluso el estudio biográfico de dos de sus máximos referentes, como Tristán Marof y Roberto Hinojosa, obliga al historiador a ampliar la mirada en términos espaciales y considerar el análisis de las redes políticas e intelectuales que se entretejieron en aquellos años. Esto, a la vez, exige la recuperación y consulta de archivos ubicados en diferentes latitudes, y aquí radica uno de los aportes más significativos de la obra: la incorporación de documentos inéditos, difíciles de consultar y para muchos lingüísticamente inaccesibles, como los del Archivo Nacional de la Historia Sociopolítica de Rusia. En este sentido, además de los siete textos analíticos y expositivos que componen la primera parte, la obra ofrece un amplio corpus documental que incluye cartas, panfletos, manifiestos, críticas, proclamas, informes y otro tipo de escritos que permiten al lector conocer en mayor profundidad el pensamiento que se generó desde las izquierdas radicales en Bolivia en particular y América Latina en general.

Los años que abarca la obra son, ciertamente, singularmente agitados a nivel regional. Desde el plano internacional, las convulsiones que se vivieron en México y Rusia permearon el ideario revolucionario latinoamericano a lo largo de la década de 1920; mientras que las catástrofes humanas y materiales ocasionadas por la Primera Guerra Mundial pusieron en tela de juicio el Progreso y la Civilización que se pregonaban desde el viejo continente. Más aún: el antiimperialismo fue, como bien apuntan Schelchkov y Stefanoni, una "marca de la época” y sobra decir, de la región latinoamericana. El Ariel de José Enrique Rodó es sin duda la expresión más emblemática, pero no la única, de este antiimperialismo, el cual en buena medida se encargó de denunciar la intromisión militar, política y económica de Estados Unidos. Buena parte de la juventud latinoamericana de la década de 1920 enarboló la bandera del arielismo a través de movimientos como la Reforma Universitaria de Córdoba, la Alianza Popular Revolucionaria Americana (APRA) o las ideas plasmadas en la revista Amauta, dirigida por José Carlos Mariátegui, por mencionar algunos.

Para la década de 1930, después de la Gran Depresión, fue más bien el paradigma del liberalismo económico y político el que fue cuestionado. Así, durante los gobiernos de Lázaro Cárdenas en México, Getúlio Vargas en Brasil, Hipólito Yrigoyen en la Argentina y la experiencia de la República Socialista de Chile, el Estado tuvo un papel predominante en los aspectos políticos, económicos y sociales de cada país. Las políticas proteccionistas y de expropiación fueron distintivas de estos gobiernos, guiados por un nacionalismo revolucionario, que en algunos casos se transformaron en dictaduras militares.

En Bolivia el militarismo se expresó en los distintos golpes que ocurrieron, así como en las prácticas políticas ejercidas durante los años de 1920 a 1940. Esto motivó que muchos intelectuales y dirigentes comunistas y anarquistas salieran de Bolivia a buscar exilio en Europa o en distintos países de América Latina. Si bien en un inicio Marof e Hinojosa salieron de su país en calidad de diplomáticos, la radicalidad de sus discursos y la transición a gobiernos bolivianos menos democráticos los obligaron a experimentar el exilio. $\mathrm{Al}$ respecto, los capítulos biográficos sobre estos intelectuales ofrecen un acercamiento a las prácticas y las experiencias que estos dirigentes desarrollaron fuera de Bolivia, así como a las distintas redes intelectuales y organizativas cuya interacción se refleja en los intercambios epistolares o en las publicaciones en la prensa.

Este aporte es particularmente significativo, en tanto que ofrece importantes reflexiones e información sobre la izquierda boliviana y latinoamericana desde una perspectiva de la historia transnacional. Como explica Hernán Topasso en el capítulo biográfico sobre Tristán Marof, la recepción y apropiación de ideas de otros intelectuales con los que mantuvo comunicación, como Henry Barbusse, Raúl Haya de la Torre, José Carlos Mariátegui, Manuel Ugarte, entre muchos otros, explica en buena medida el perfil multifacético de Marof. Sus obras son la expresión de un pensamiento de izquierda que se considera comunista, nacionalista, 
indianista, aintiimperialista e incluso trotskista. Pero además de ello, la situación misma del país que recibió a los intelectuales bolivianos debe considerarse en el análisis de sus ideas. Marof, por ejemplo, mostró un gran interés e incluso admiración por las políticas anticlericales y nacionalistas que se desarrollaron en México después de la revolución.

Finalmente, cabe destacar el extenso material documental que se anexa en la segunda parte de la obra y que, por un lado, permite complementar y profundizar en las temáticas desarrolladas en los capítulos anteriores; y por otro, sirve como un excelente material de análisis e investigación para los interesados en la historia de la izquierda latinoamericana de aquellos años, tema que en los últimos años ha tenido una especial atención. Así, con estos documentos anexados se pueden leer informes dirigidos a la Internacional Comunista, la correspondencia entre Marof y distinguidos intelectuales como Mariátegui y Ugarte, las intervenciones en las distintas Conferencias de los Partidos Comunistas de América Latina o los distintos análisis que publicaban los partidos y organizaciones bolivianas de corte socialista, comunista o anarquista.

Esta obra es, en definitiva, un referente para el estudio de la historia intelectual boliviana, nutre la historiografía sobre las izquierdas en América Latina y, por otra parte, permite ver las posibilidades teóricas y metodológicas que se pueden implementar para el estudio del pensamiento político nacional desde una perspectiva trasnacional. 